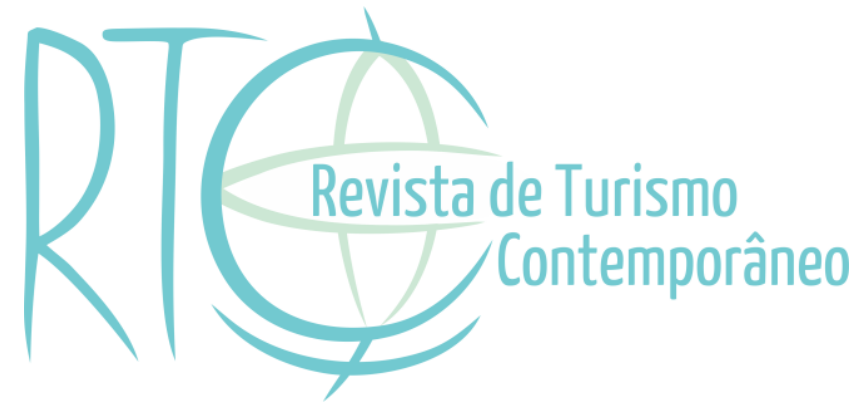

\title{
O setor hoteleiro na praia de Canoa Quebrada/CE: Processo de expansão urbana e turística
}

\section{The hotel sector on the beach of Canoa Quebrada/CE: tourism and urban expansion process}

Felipe de Souza Siqueira

Professor do Instituto Centro de Ensino Tecnológico - CENTEC, Aracati/CE, Brasil E-mail: felipesiqueira50@gmail.com

\section{Débora Goes Urano}

Mestranda do Programa de Pós-graduação em Turismo da Universidade Federal do Rio Grande do Norte - UFRN, Natal/RN, Brasil

E-mail: debby104@hotmail.com

Raquel Maria Fontes do Amaral Pereira

Professora da Universidade Vale do Itajaí - UNIVALI, Itajaí/SC, Brasil

E-mail: raquelfontespereira@gmail.com

Artigo recebido em: 31-08-2015

Artigo aprovado em: 08-03-2017 


\title{
RESUMO
}

Este artigo discute a expansão da atividade turística na praia de Canoa Quebrada - Ceará, buscando entender suas implicações sobre o desenvolvimento do setor hoteleiro a partir das iniciativas pioneiras na década de 1970 até sua ampliação nos dias atuais. Seu foco principal é o setor hoteleiro, sua expansão e as transformações decorrentes do crescimento urbano e dos fluxos turísticos, abarcando as origens e as principais características desse setor, bem como a sua relação com a evolução da localidade. A operacionalização da pesquisa impôs a definição de um referencial teórico apropriado ao entendimento do processo de expansão da cidade e dos fluxos turísticos, de modo a propiciar a apreensão da totalidade dos elementos naturais e humanos definidores da realidade investigada. A análise dos processos locais relativos à expansão urbana e turística exigiu a sua articulação ao contexto regional e nacional, bem como a consulta à obras capazes de oferecer elementos acerca da realidade objeto da investigação, elucidando aspectos relacionados às origens e a evolução do setor hoteleiro, decorrentes de transformações sócio espaciais ocorridas em Canoa Quebrada.

Palavras-chave: Canoa Quebrada. Setor Hoteleiro. Turismo.

\begin{abstract}
This paper discusses the expansion of tourism on the beach of Canoa Quebrada, Ceará, seeking to understand its implications on the development of the hospitality industry from pioneering efforts in the 1970s to its expansion today. Its main focus is the hospitality industry, its expansion and the changes resulting from urban growth and tourism, covering the origins and main features of this sector, as well as its relationship with the evolution of the locality. The operationalization of the research imposed the definition of an appropriate theoretical framework to the understanding of the city's expansion process and tourists flows, so as to facilitate the arrest of all the natural and human elements that define the investigated reality. The analysis of local processes involving the urban and tourism expansion demanded its articulation to the regional and national context as well as the consultation of others works also able to offer elements about the reality of the research object, clarifying aspects related to the origins and evolution of the hotel industry due to socio-spatial transformations that occurred in Canoa Quebrada.
\end{abstract}

Keywords: Canoa Quebrada. Hotel Industry. Tourism. 


\section{INTRODUÇÃO}

O presente artigo tem como eixo central a discussão acerca da origem e evolução do setor hoteleiro da praia de Canoa Quebrada/Ceará, frente às transformações decorrentes da expansão urbana e da atividade turística. Ao longo do texto, o espaço urbano é interpretado como produto de relações historicamente determinadas, pelo processo capitalista de produção, que imprime suas marcas sobre a materialidade.

O trabalho representa parte de pesquisa realizada para a dissertação de mestrado, tendo como recorte espacial a praia de Canoa Quebrada, localizada no litoral leste do estado do Ceará, cuja organização sócio-espacial vem passando por um acelerado processo de transformação imposto pelo seu próprio crescimento populacional e pelo aumento dos fluxos turísticos decorrentes da expansão das relações capitalista de produção no país.

O foco central do trabalho de pesquisa era investigar as origens e a evolução do setor hoteleiro local, da década de 1970 até 2015. Para tanto, a análise fundamentou-se na aplicação do paradigma de formação sócio-espacial que se insere numa perspectiva teórica que permite o resgate da categoria espaço na análise da formação econômica e social, dentro de uma perspectiva ligada ao materialismo histórico-dialético, abrindo novas e importantes possibilidades de explicação de realidades concretas.

A abordagem científica da temática em questão permitiu levar em consideração a relação dialética entre os elementos naturais e humanos em diferentes escalas: mundial, nacional, regional e local, visto que conforme Santos (1986), "a História não se escreve fora do espaço e não há sociedade a-espacial. O espaço, ele mesmo, é social". Tal implica em considerar as características físicas do espaço onde se originou e desenvolveu a cidade e, por consequência, a história da sociedade que aí se implantou.

Milton Santos (2012) salienta ainda que o espaço não é formado apenas por coisas, objetos geográficos de origem natural, fruto da ação da natureza. $\mathrm{O}$ espaço é isso mais a sociedade que ali se instala e vive, pois cada fração da natureza abriga uma fração da sociedade. Partindo desta premissa, a investigação acerca das origens e das transformações ocorridas no traçado urbano, bem como no setor hoteleiro de Canoa Quebrada foi interpretada a partir de uma base teórica, que se apoia na intenção de conhecer a sociedade local na sua totalidade e nas suas frações a partir da compreensão de que existe uma relação dialética entre os vários elementos que constituem essa realidade, sejam eles de ordem natural ou humana.

$\mathrm{O}$ artigo apresenta-se dividido em duas partes. A primeira delas tem foco nos reflexos da atividade turística na organização sócio-espacial de Canoa Quebrada. Já a segunda 
aborda a evolução da hotelaria em Canoa Quebrada, mostrando as transformações ocorridas por conta do crescimento do turismo nas últimas décadas.

\section{METODOLOGIA}

No que tange às técnicas e aos métodos de pesquisa, o trabalho caracteriza-se por uma abordagem qualitativa, por sua validade como suporte para apreender a complexidade do tema investigado, permitindo assim, "compreender e classificar processos dinâmicos vividos por grupos sociais e possibilitar, em maior nível de profundidade, o entendimento das particularidades do comportamento dos indivíduos" (Richardson, 1999, p. 43). A pesquisa qualitativa permite a aquisição de um conhecimento mais denso de casos específicos, sendo a mais utilizada nas ciências sociais.

A investigação, por um lado, encontrou apoio em concepções teóricas e por outro exigiu um levantamento de dados empíricos que permitissem descrever e interpretar as diferentes etapas da evolução urbana e da atividade turística na praia de Canoa Quebrada, identificando os elementos responsáveis por essa expansão, as principais características dessa dinâmica e o desenvolvimento da atividade turística, no que diz respeito, principalmente, ao setor hoteleiro.

Assim, para assegurar o êxito dos propósitos traçados, optou-se pela realização de uma pesquisa histórica e exploratória, de caráter qualitativo. Segundo Gil (2002), a pesquisa exploratória proporciona maior familiaridade com o problema, com vistas a torná-lo mais explícito ou a construir hipóteses. O seu planejamento é também bastante flexível, o que possibilita a consideração dos mais variados aspectos relacionados ao fato objeto da análise.

Foi realizada, também, pesquisa bibliográfica e levantamento de dados junto aos órgãos públicos, tais como o Instituto de Pesquisa e Estratégia Econômica do Ceará (IPCE) e o Instituto Brasileiro de Geografia e Estatística (IBGE), na busca de informações históricas sobre as origens e evolução da praia de Canoa Quebrada. Foi, igualmente, consultado o acervo da Biblioteca Pública do Estado do Ceará e do Instituto do Ceará, bem como o das bibliotecas de Universidades e Faculdades.

Realizada em junho de 2013 e atualizada em agosto 2015, a pesquisa de campo foi feita por meio de observação não-participante in loco, registros fotográficos e realização de entrevistas. A amostra foi intencional, tendo sido escolhido um pequeno grupo de pessoas de modo não aleatório, mas seguindo critérios de representatividade social (Thiollent, 1997). 
Nesse sentido, foram entrevistados alguns moradores mais antigos e empresários do setor turístico.

\section{REFLEXOS DA ATIVIDADE TURÍSTICA NA ORGANIZAÇÃO SÓCIO ESPACIAL DE CANOA QUEBRADA}

A origem de Canoa Quebrada está relacionada ao mar que sempre exerceu influência nas atividades econômicas e culturais da localidade. A pesca e atividades correlatas, como as conservas e salga de peixe, estão presentes desde a origem deste povoado garantindo o sustento dos seus habitantes. Até o final dos anos 1960, essa localidade se assemelhava a muitas outras do litoral do Nordeste brasileiro, com praias tranquilas e uma vida simples, típica das vilas de pescadores artesanais.

De acordo com dados do censo de 2010 realizado pelo IBGE, Canoa Quebrada é considerada uma área urbana isolada - AUI, por se tratar de área urbana definida por lei municipal, separada da sede do município por uma área rural ou por outro limite legal. A AUI de Canoa Quebrada é composta por cinco setores censitários, e possui uma população total de 2.918 habitantes, sendo composta por 1.491 domicílios (IBGE , 2015).

Situada sobre falésias de até 30 metros acima do nível do mar, Canoa Quebrada localiza-se na área litorânea do município de Aracati, distante $12 \mathrm{~km}$ da sede municipal e 165 km da capital do estado, sendo considerada, no entanto, área urbana de Aracati pela prefeitura municipal. O acesso a Canoa Quebrada pode ser feito por rodovias federais e estaduais. A BR-304 é sua artéria principal, possuindo entroncamento com a BR-116, ambas integrantes da malha rodoviária federal; já as CE's 040 e 276 pertencem à malha rodoviária estadual.

A primeira ocupação da praia de Canoa Quebrada dar-se-á abaixo das falésias na beira do mar. Com o avanço da maré, porém, as famílias foram obrigadas a transferir suas residências para a parte de cima. A partir do século $\mathrm{XX}$, tem-se um grande número de migrações da beira-mar para cima das falésias. A igreja foi transferida na década de 1930. Atualmente, a área da praia só tem as barracas, as quais vem sofrendo há alguns anos com a forte alta das marés.

Contudo, o ponto de partida para a urbanização da vila de Canoa Quebrada data da década de 1970 e está intimamente ligada à história do turismo, pois nesse período é que começaram a chegar os primeiros visitantes e a localidade passou a se destacar como um dos símbolos do "estilo de vida alternativo". Segundo Barros (2004), os primeiros visitantes de 
Canoa Quebrada teriam sido médicos franceses, em 1968, integrantes de um grupo em missão científica no Brasil que atendia os doentes em Marjorlândia, praia vizinha de Canoa Quebrada. Uma vez ou outra iam à Canoa Quebrada para atendimento da comunidade e filmagens.

Entretanto, na metade da década de 1970, Canoa Quebrada começa a despontar para alguns como o 'paraíso hippie'. Não há, entretanto, indícios de que estes visitantes eram realmente hippies. De acordo com o empresário Élcio Antônio Fernandes ${ }^{1}$, em informação prestada verbalmente, muitos desses visitantes eram mochileiros e ao desembarcar de ônibus em Aracati eram tachados de hippies, pois chegavam de mochila nas costas. Provenientes de distintos lugares do Brasil e do mundo, a maior parte deles tinha os cabelos compridos, usava barba e vestimentas diferentes. Esse fato gerou, também, a fama da praia ser ponto de maconheiros e de perversão, pela prática do nudismo. Nessa época, o acesso à vila de pescadores era precário, pois, ainda, não existia estrada pavimentada para a localidade, sendo o único acesso realizado por meio de trilhas, em boa parte realizada pelas dunas.

Da metade da década de 1970 até os dias atuais, a massificação do turismo em Canoa Quebrada, foi fruto da expansão da atividade turística. Assim tornou-se um dos principais destinos turísticos do Ceará, colocando o município de Aracati entre um dos 65 destinos indutores do Brasil, em razão de sua bela paisagem e das noites animadas com diversos estilos musicais, atraindo pessoas de todos os lugares do mundo e transformando a vila de Canoa Quebrada em um espaço turístico urbanizado.

Conforme Boullón (2005), a existência do espaço turístico está condicionada à presença de atrativos turísticos. Estes são a matéria-prima do turismo, uma vez que constituem a causa principal que motiva uma viagem turística. Canoa, então, dotada de belas paisagens litorâneas, cercada por dunas e falésias tinha a matéria-prima nescessária para o desenvolvimento da atividade turística.

Com condições e infraestrutura para o desenvolvimento do turismo, Canoa Quebrada passa a ser identificada como local de lazer, sendo transformada e produzida para o turismo. A organização espacial foi sendo alterada ao longo dos anos, impulsionada pelo modo de produção capitalista, trazendo recursos para Canoa Quebrada, mas também grandes perdas culturais e patrimoniais, gerando vários problemas decorrentes da urbanização, principalmente, nas áreas de falésias e dunas.

\footnotetext{
${ }^{1}$ Proprietário da empresa ArtCanoa, que vende objetos artesanais, e que chegou a Canoa Quebrada aos 18 anos, em fevereiro de 1978, vindo de Santo André -SP.
} 
Ainda, segundo Boullón (2005, p. 31):

O funcionamento do espaço turístico exige uma superestrutura administrativa integrada pelas organizações de empresa privada e pelos organismos do estado que se especialize em definir e harmonizar o conjunto de normas e critérios que regulamentam as formas operacionais do setor.

Foi a partir da década de 1990, que Canoa Quebrada começou a ser vista como um polo turístico de grande potencialidade. A instalação de empreendimentos ligados à inciativa privada, após o investimento do setor público em infraestrutura, como energia elétrica, água encanada e estradas, ofereceu as condições mínimas para a expansão das atividades turísticas.

$\mathrm{Na}$ década de 1990, surgiram empreendedores com destaque para os estrangeiros (holandeses, italianos, espanhóis, dentre outros) e pessoas provenientes de outros Estados do Brasil. Começa, assim, a prática de construção massificada de estabelecimentos de hospedagem e alimentação que são, na maioria dos casos, de propriedade de algumas pessoas que chegaram, inicialmente, como turistas e acabaram por se fixar nesse lugar, montando seus próprios negócios e criando um centro turístico.

Os centros turísticos, conforme salienta Boullón (2005),

São os principais elementos que compõem o espaço turístico, pois se comportam como uma economia de aglomeração que facilita a integração ou complementação das diferentes categorias e tipos adotados pelos serviços turísticos ali instalados.

Para esse mesmo autor, os serviços ao turista podem ser classificados nas sete categorias seguintes: hospedagem, alimentação, passeios, esportes, comércio de artigos tipo souvenirs, transportes e agência de viagens.

A vila de Canoa vive um processo de urbanização subordinado à lógica da atividade turística, dos negócios e, do núcleo urbano, fazendo emergir um centro turístico, que agora, se desenvolve em função do consumo das paisagens e do espaço social habitado, fazendo surgir um novo modo de vida urbano, novas formas de paisagem e, por conseguinte, um novo território - o território turístico - assinalado pela descaracterização do espaço original e do modo de vida.

De acordo com Cruz (2006), o turismo se dá na escala e na efervescência da vida nos lugares e mesmo nos lugares cuja vida está profundamente imbricada à atividade do turismo. Sua existência sempre vai além das lógicas impostas por essa atividade. Em Canoa Quebrada, o processo de reprodução do espaço, originado pelo boom da atividade turística, evidencia a expulsão, por parte do capital, dos moradores locais cujas residências estavam localizadas mais próximas da orla marítima e da rua central - Broadway - para dar lugar aos restaurantes, 
bares e pousadas, provocando, assim, uma redefinição espacial, muito embora esse espaço não apresente divisas ou fronteiras.

Assim sendo, o espaço turístico perde e ganha valor com as interferências que nele se processam, transformando as localidades de forma diferenciada. Em Canoa Quebrada, a ocupação territorial como destacado, anteriormente, deu-se de forma desorganizada, resultante da falta de políticas públicas para a implantação de negócios ou imóveis, o que gerou condições propícias para ocupações desordenadas e disputas pelo espaço geográfico entre os moradores nativos e estrangeiros.

Deste modo, a procura pelo espaço turístico, anteriormente utilizado apenas pelos nativos (pescadores), começa a provocar um intenso e abrupto processo de transformação, decorrente de toda uma ocupação espacial e urbana necessária ao fazer turístico, originando um processo de reordenamento sócio espacial da comunidade nos últimos anos. Portanto, com a chegada do turismo, os espaços antes não-urbanizados de pequenas localidades como Canoa Quebrada, passam a desenvolver uma infraestrutura urbana em prol da atividade turística.

Krippendorf (2009) não considera o desenvolvimento do turismo como um fim em si, para ele o crescimento do turismo gera, o aumento das pessoas que chegam, o aumento da capacidade de alojamentos, de transporte e da entrada de divisas, porém isso, não necessariamente, implica em crescimento econômico para a comunidade. $\mathrm{O}$ autor, ainda, afirma que uma comunidade turística deve conservar o poder sobre o solo. A política e o planejamento do solo são, indiscutivelmente, os instrumentos-chaves que proporcionam às regiões turísticas o controle sobre o desenvolvimento turístico.

Assim, o aumento dos fluxos migratórios de turistas, de certa forma, contribuiu para o processo de urbanização de Canoa Quebrada, o que não difere de outras localidades turísticas $^{2}$, nas quais se registram um aumento dos fluxos migratórios de mão-de-obra relacionada à atividade turística, que emerge na localidade, muito embora a própria atividade turística demande mão de obra local, o que contribui para intensificar esses fluxos.

Assim, nos últimos 40 anos, a estrutura produtiva local passou por uma intensa transformação, a qual, por sua vez, viria a induzir outras atividades e o crescimento populacional. As mudanças ocorridas na estrutura físico-territorial foram intensificadas mais

\footnotetext{
2 Em recente artigo publicado na Revista Turydes, ao analisar o crescimento dos centros urbanos litorâneos do litoral do estado de Santa Catarina, onde houve igualmente um expressivo aumento da demanda turística, Pereira destaca que devido a popularização do veraneio e a dinamização das atividades turísticas, os municípios situados na orla catarinense passaram a "conhecer ritmos diferenciados de ocupação e crescimento, o que fez com que alguns deles se tornassem muito cedo centros de atração de fluxos de veranistas e turistas, enquanto outros foram afetados só muito recentemente" (Pereira, 2013, p.10)
} 
ainda após a década de 1990, com a chegada da água encanada, energia elétrica e estrada asfaltada.

Pode-se afirmar, portanto, que a expansão urbana de Canoa Quebrada, de certa forma, surgiu como um processo subordinado à lógica da atividade turística. O núcleo urbano se desenvolve em função do consumo das paisagens e do lazer, fazendo emergir um modo de vida urbano, novas paisagens e, por conseguinte, um novo território - "território turístico"marcado pela descaracterização do lugar, com projeção de um novo modo de vida.

\title{
4 EVOLUÇÃO DA HOTELARIA EM CANOA QUEBRADA
}

Os primeiros estabelecimentos de apoio ao turismo em Canoa Quebrada datam da década de 1970, tendo sido pioneiro Adolfo Alves dos Santos. De acordo com Grandelle (2015), ele

\begin{abstract}
Recebeu os primeiros turistas de Canoa Quebrada em meados dos anos 70. Como os turistas eram muito brancos, a população tinha medo daqueles que julgavam ser vampiros. Seu Adolfo para receber melhor esses hóspedes, abriu o alpendre na sala da sua casa que funcionara como o primeiro restaurante de Canoa.
\end{abstract}

Segundo relato verbal feito por Adolfo Neto em junho de 2013, isso ocorreu no período de 1972 a 1975. Ainda de acordo com depoimento do mesmo, nos três primeiros anos somente seu avô tinha uma hospedaria, em seguida foram surgindo outras.

Conforme Esmeraldo (2002, p. 85), além da casa de seu Adolfo, os nativos alojavam os turistas nas suas próprias casas. Quando gostavam do visitante deixavam passar o tempo que quisessem; quando não gostavam, pediam para que saíssem das suas casas. Dá para observar que não existia, nesse primeiro momento, uma relação comercial, ou seja, não havia uma relação de mercado capitalista.

Hoje a casa do Sr. Adolfo é administrada pelos seus filhos e conta com oito quartos para alugar. Não tem uma estrutura como a das pousadas mais modernas e encontra-se como desativada no cadastro da SETUR/CE. Na mesma década, surgiu a pousada da Maria Alice, que ainda está em atividade. Após uma reforma, ela funciona com quartos em cima e lojas no piso térreo, compondo um centrinho comercial juntamente com outras lojas de suvenires, mercadinhos, entre outros estabelecimentos.

Na década de 1980, a pousada assegurava o fornecimento de energia por meio de um gerador próprio que ficava próximo a praia. Após a morte de Maria Alice, no ano 2002, a administração da pousada ficou sob a responsabilidade de sua nora Maria Auxiliadora. 
Atualmente conta com 16 unidades habitacionais (UHs) e 38 leitos. Giorgio Guerzoni, atual proprietário do Hotel Tropicália (relato verbal), conta que na segunda vez que veio a Canoa Quebrada ficou hospedado na pousada de dona Maria Alice, que oferecia a melhor estrutura da época.

A pousada da Dona Didi também é uma das que foram instaladas em meados da década de 70. Começou, também, como as outras duas, alugando rede e depois um quarto para hospedar os turistas. Localizada na Avenida Dragão do Mar, popular Broadway, a hospedagem fica no andar superior, atualmente com 10 UH's e 20 leitos, e o térreo destina-se ao comércio.

Os hotéis originários da década de 1970, de propriedade de nativos, não suportaram a competitividade de uma hotelaria mais moderna com inovações tecnológicas implementadas pelos estrangeiros e brasileiros oriundos de outras regiões do país, perdendo espaço no mercado e deixando de funcionar como estabelecimentos para hospedagem. Por isso, passaram a investir em outros segmentos como, por exemplo, o comércio. Muitos deles transformaram as suas instalações para a implantação de centros comerciais, utilizando a parte inferior para o comércio, como foi o caso das pousadas de Dona Didi e Maria Alice, conforme figuras (1) e (2).

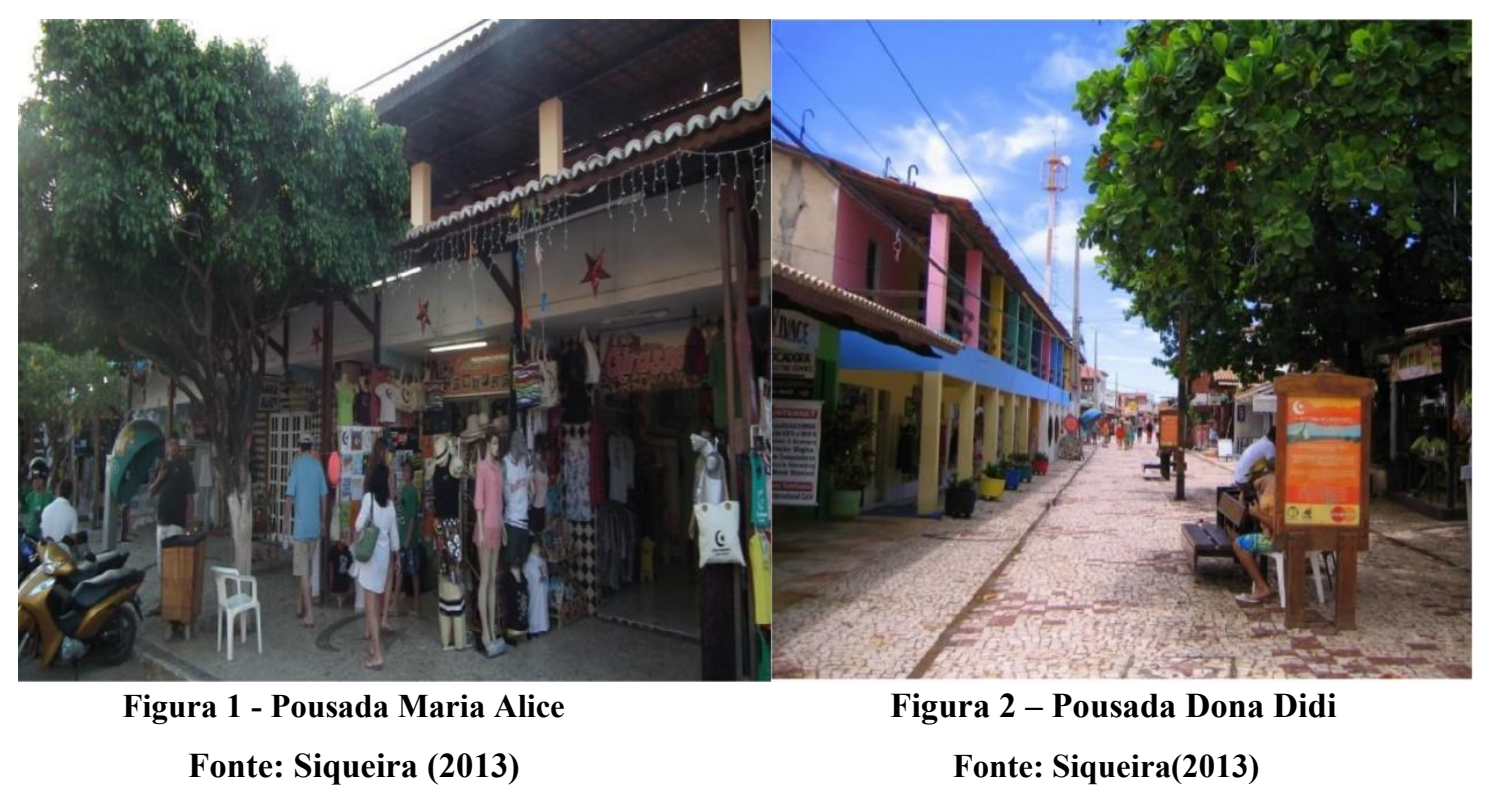

As primeiras pousadas da década de 1970/80 a surgirem na praia de Canoa Quebrada localizavam-se no setor mais central da localidade. Na figura (3) pode-se observar, também, que corresponde a maior parte da Av. Dragão do Mar, conhecida como Broadway. 


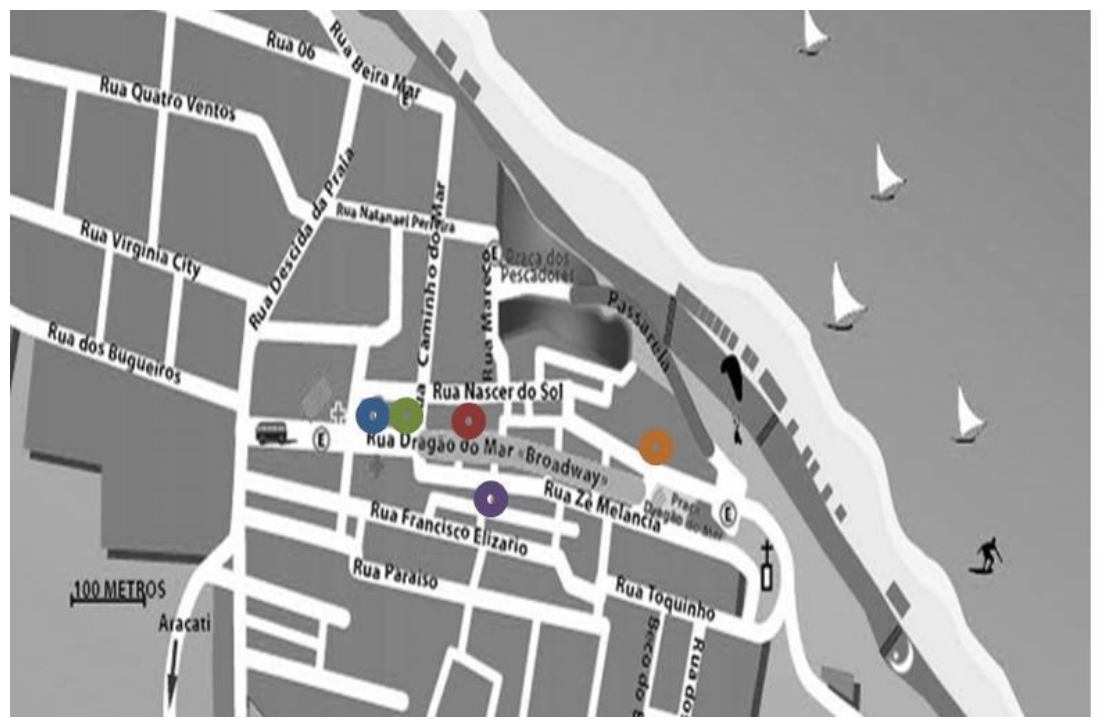

\section{Adolfo pousada}

Pousada da Didi

- Pousada Maria Alice

- Pousada Latitude

- Pousada Lua Morena

Figura 3 - Localização das pousadas-décadas de 1970 / 80

Fonte: (Siqueira , 2013)

Já na década de 80, surgiram duas novas pousadas: Lua Morena e Latitude. A pousada Lua Morena surge por volta de 1984, de acordo com informações verbais de Toinho Correia, tendo como proprietário Miguel Correia, natural de Aracati, e inicialmente dispunha de 8 chalés. No ano de 2000, foi ampliada para 16 chalés e passou a ser administrada por Jean Pierre. Foi a primeira a ter água encanada movida por um cata-vento e, também, uma das primeiras a fazer uso de telefone em Canoa Quebrada. Na parte central do terreno onde está situada a pousada, há uma residência datada da década de 1970 umas das primeiras no estilo de veraneio com varanda de fora a fora.

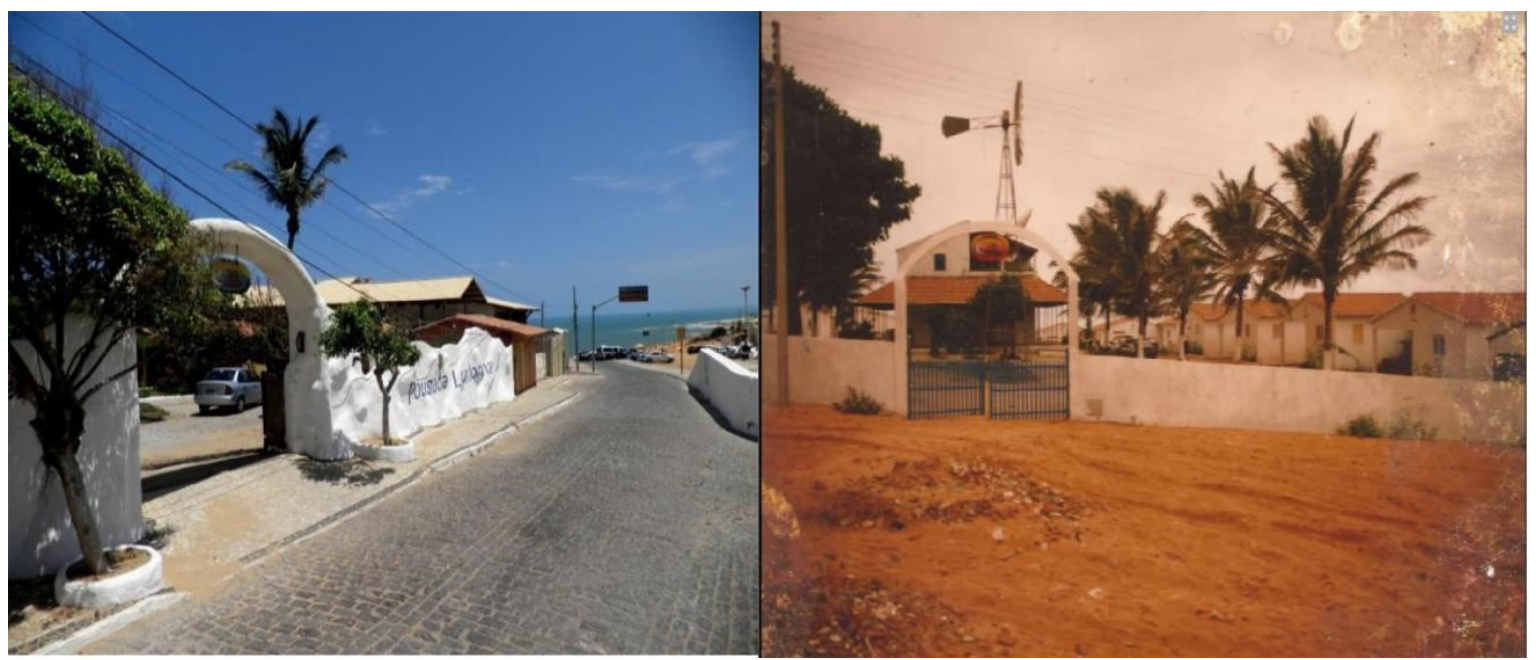

Figura 4 - Pousada Lua Morena (2013)

Fonte: (Siqueira , 2013)
Figura 5 - Pousada Lua Morena (1984)

Fonte: (Pousada Lua Morena, 2013) 
A Pousada Latitude também situada na Av. Dragão do Mar (Broadway), foi instalada por dona Roseli, empreendedora oriunda da região amazônica brasileira, no início da década de 1980. Na época, a pousada foi construída com carnaúba, especialmente seu telhado e sua base de sustentação. Numa área de mais de $1.000 \mathrm{~m}^{2}$, foi levantado um prédio de três pavimentos, dando origem, assim, a uma das primeiras pousadas de Canoa Quebrada.

No final da década de 1990, a amazonense Rosely resolveu voltar para sua terra natal e arrendou a pousada para o casal mineiro, Paulo e Cacilda. O casal, que naquela época já tinha outros investimentos em Canoa Quebrada, convidou Marta, mãe de Paulo, para assumir a gerência da pousada Latitude. Em 2006, o casal mineiro comprou, definitivamente, a pousada deixando na administração os pais de Paulo, Rui Barbosa Soares e Marta Soares, que fizeram várias reformas e melhorias na pousada. Como os demais meios de hospedagem que surgiram na Broadway, a pousada conta, na sua infraestrutura, com o Latitude Center, um mini shopping com caixas eletrônicos do Banco do Brasil e Bradesco, Agência dos Correios, Casa Lotérica e uma loja de moda esportiva unissex.

O surgimento do setor hoteleiro de Canoa Quebrada, mais ligado às relações comerciais capitalistas, por sua vez, dar-se-á no final da década de 1980, com a chegada das redes de energia elétrica e água encanada, respectivamente nos anos de 1989 e 1992. Essas duas novas infraestruturas favoreceram a construção de estabelecimentos hoteleiros de imigrantes de outros estados e países, principalmente, os europeus.

Com o passar dos anos, a população de Canoa Quebrada assistiu às transformações de sua organização espacial em decorrência do aumento significativo do setor hoteleiro e de alimentação. Além disso, diversas obras e medidas relacionadas à infraestrutura foram implantadas pelo governo do estado permitindo que Canoa Quebrada recebesse um maior fluxo turístico, com destaque para a pavimentação do acesso até a sede do município.

Até o final da década de 1980 e início dos anos de 1990, a rede hoteleira de Canoa Quebrada era pacata e calma, com poucos prédios construídos. Porém, diante da melhoria de sua ligação com a rede rodoviária nacional e estadual e outras infraestruturas criadas pelo Prodetur/CE, começa, após a década de 90, o incremento do fluxo migratório, a instalação de várias pousadas e um aumento da atividade turística, bem como do mercado imobiliário. Fica clara, então, a real mudança do espaço local.

$\mathrm{Na}$ década de 1990, merece destaque o surgimento de alguns empreendimentos do setor hoteleiro dentro da área central de Canoa Quebrada, como a construção do Hotel 
Tropicália, da Pousada Falésia, da Pousada do Toby e o Resort Porto Canoa, localizado entre as praias de Canoa Quebrada e Marjorlândia.

O Hotel Tropicália é de propriedade de Giorgio Guerzoni, italiano que veio ao Brasil em busca de um lugar para fazer um bom investimento. Segundo relatos do próprio Guerzoni, ele veio subindo a procura de um bom lugar para fazer sua pousada, começando pelo litoral baiano onde passou por Porto Seguro e Porto de Galinhas, em Pernambuco, que já eram áreas bem mais exploradas do que Canoa na década de 1980. A partir de 1992, ele inicia a construção do atual Hotel Tropicália que conta com 20 apartamentos e 78 leitos.

A Pousada do Toby foi construída em 1990 e parte do sonho de dois dinamarqueses, Torben e Frank. Essa parceria resultou na concretização de um prédio de três andares, o primeiro verticalizado de Canoa Quebrada, localizado na rua Leandro Bezerra, a uma distância de 60 metros da Broadway. Possui 23 Uhs, 66 leitos, e ainda tem, na sua cobertura, um bar e restaurante.

O Falésia Praia Hotel começou a funcionar no dia 31 de dezembro de 1994, a partir dos ideais empreendedores do Sr. Moisés, que largara o Banco do Nordeste (BNB) para se fixar como empresário do setor hoteleiro em Canoa Quebrada. Seu nome deriva das formações de barreiras arenosas que formam as falésias de Canoa Quebrada. O Hotel está localizado na rua Sudoeste, a $200 \mathrm{~m}$ da praia e da Broadway. Hoje, o hotel encontra-se sobre responsabilidade da esposa do Sr. Moisés, Maria Salete Santigo e seu filho, Igor Santiago Moisés.

No ano de 1996, pode-se destacar a inauguração do maior empreendimento hoteleiro de Canoa Quebrada, o Porto Canoa Resort com bandeira Best Western, do empresário Francisco Clodomir Rocha Girão. O empreendimento possuía uma infraestrutura com salão de convenções, um amplo auditório para reuniões com capacidade para 130 pessoas e duas salas para serviços de apoio a eventos como seminários, congressos e treinamentos. Possuía, ainda, dois restaurantes: o Villa dos Pescadores e o Restaurante Porto Canoa Sea Club; um parque aquático, lojinhas, além de um hotel com 166 apartamentos, uma pousada com 20 apartamentos e três condomínios, que totalizavam 96 apartamentos.

O resort permaneceu em atividade por dez anos até seu fechamento total. Hoje, no local, funcionam somente os três condomínios com aluguel de apartamentos para mensalista e por temporada. Na década de 1990, surgiram, ainda, outros empreendimentos hoteleiros na AUI de Canoa Quebrada, conforme tabela (1) apresentada abaixo com 25 meios de hospedagem que tinham cadastro na secretaria de turismo na década de 1990. 
Tabela 1- Meios de hospedagem da década de 1990

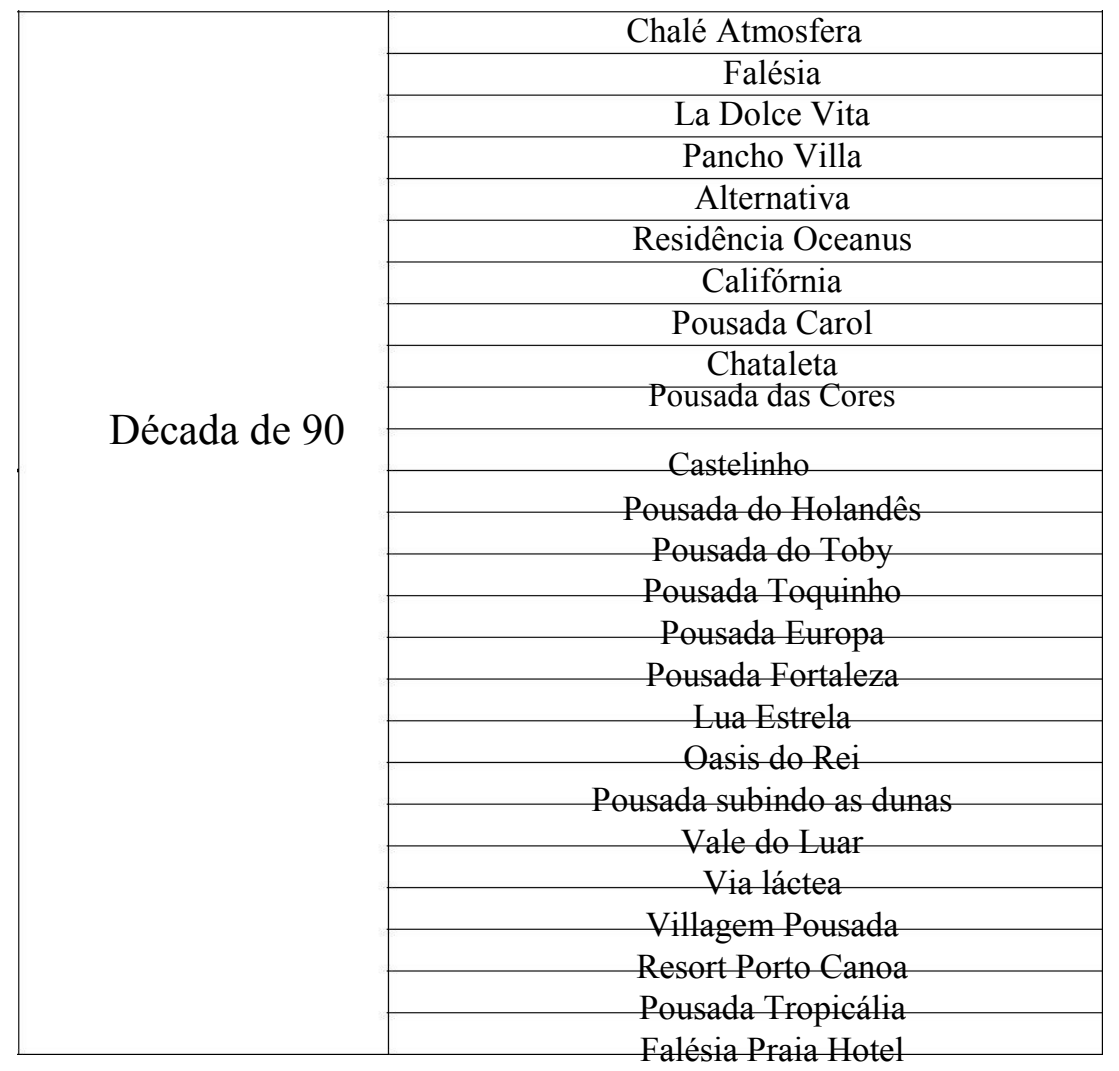

Fonte: Setur/CE (2015) adaptado pelo autor.

Já na década de 2000, começa a ocorrer uma intensa ocupação no lado oeste da AUI (área de interesse urbano) de Canoa Quebrada por parte do setor hoteleiro. É ali que se instalam, por exemplo, a Pousada 7 Mares, o Hotel Long Beach, a Pousada Missare, a Pousada Presidente Hotel e a Pousada Aruanã, lado este que, até então, era ocupado apenas por dunas e pelo cemitério, sendo, também, utilizado para prática do nudismo.

Uma das primeiras pousadas a ocupar esse setor foi a Pousada 7 Mares, que surgiu do empreendedorismo de um jovem casal oriundo de Fortaleza, Veronica e Guilherme, em julho de 2000. Segundo informação verbal do proprietário, o mesmo abriu seu negócio em Canoa Quebrada após aderir ao programa de demissão voluntária no Banco do Estado do Ceará (BEC), que iria ser privatizado. O programa proporcionou o capital para montar o negócio, além da realização de vários cursos na área de empreendedorismo, hotelaria, alimentos e bebidas e outros.

Depois de um demorado processo de estudo de viabilidade e pesquisa de mercado, e de ter visitado várias praias no litoral, decidiram-se por Canoa Quebrada para a sede de seu empreendimento. A pousada iniciou sua operação com 5 chalés, sendo que o casal morava em um deles e alugava os outros quatro. Hoje, a pousada conta com 7 chalés e 3 apartamentos. 
Guilherme relata, ainda, as dificuldades iniciais, pois. Inicialmente. queria comprar um terreno próximo à Broadway, mas os valores não eram acessíveis. Por isso comprou o terreno em uma área ainda não tão habitada em Canoa, que não tinha estrada, energia elétrica trifásica, nem telefone. Com a construção da pousada teve que fazer o nivelamento do terreno, fazer a estrada até a pousada e puxar energia trifásica e telefone. Segundo ele, a energia trifase só chegou à região após a construção do Hotel Long Beach, em 2002.

O Hotel Long Beach representa um novo marco na hotelaria de Canoa Quebrada que, até então, não possuía um empreendimento dessa categoria (5 estrelas). Conta com salão para eventos, restaurante dentro do estabelecimento, bar, padaria, lavanderia, enfim, toda a estrutura de um grande hotel, que na região só era encontrada no Porto Canoa.

O Hotel Long Beach, inicialmente, de propriedade do Sr. Sérgio Ariu, oriundo da Itália, da região da Sardenha, foi vendido, em 2008, para o Sr. Juan José Bru Garcia, de origem espanhola, que realizou várias reformas e a expansão do hotel com a construção do Residencial Long Beach. Possui, atualmente, 64 apartamentos e 138 leitos, piscina olímpica e bar, dentro de uma área bem arborizada.

A Pousada Aruanã é uma das que foi construída após o ano 2000, fora do setor central da AUI de Canoa Quebrada, no lado oeste. Localizada na rua dos Bugueiros, s/n, em uma área de $3.600 \mathrm{~m}^{2}$. Foi construída em 2005, com 15 apartamentos, sendo logo em seguida, após a constatação da crescente demanda, construídos mais 6 apartamentos. Emanuele Samore, o proprietário da pousada, é de procedência italiana. A ocupação dessa área se dá, primeiro, porque o setor central já estava praticamente todo urbanizado e, segundo devido aos preços mais acessíveis. Vale ressaltar que o traçado das ruas é mais largo e retilíneo do que as do setor central, facilitando a circulação dos veículos automotivos.

Os estabelecimentos que surgiram após a década de 2000, trouxeram, na sua maioria, equipamentos e instalações modernas: TVs de última geração, trancas das portas com cartões magnéticos, sistema informatizado de reserva, zonas de internet wireless, entre outros, fazendo com que os equipamentos das décadas anteriores ficassem ultrapassados, o que obrigou muitos proprietários de pousadas mais antigas a reformar e modernizar seus estabelecimentos. Os que não acompanharam esse processo acabaram tendo que baixar o preço das diárias, fato que diminuiu a rentabilidade, além de forçar a melhoria da qualidade dos serviços.

Assim, como visto, no polo turístico de Canoa Quebrada, os meios de hospedagem existentes são bem diferenciados, incluindo desde as simples pousadas familiares até as mais 
luxuosas que oferecem serviços como áreas de lazer, bar e restaurantes. Atualmente, a oferta hoteleira da praia de Canoa Quebrada é composta por 84 estabelecimentos, que possuem 1.078 UHs (apartamentos) e 3.001 leitos, conforme dados coletados por pesquisa realizada pela SETUR-CE, no ano de 2014, apresentados em fevereiro de 2015. Algumas pousadas, porém, não se encontram nos cadastros da SETUR/CE, muito menos no Cadastur do Ministério do Turismo, razão pela qual esses números não correspondem à realidade, já que as pousadas existentes podem chegar a mais de 100. Os períodos considerados de maior ocupação em Canoa Quebrada são o Carnaval, a Semana Santa, o Réveillon, e a alta estação de férias que fica dividida em dois períodos de Dezembro à Março e de Junho até Agosto.

Contudo, o desenvolvimento da atividade hoteleira em Canoa Quebrada deu-se mesmo, de forma mais evidente, a partir da década de 90, acompanhando o desenvolvimento do turismo no estado do Ceará. A tabela (2), demonstra o crescimento da oferta hoteleira de 1990 a 2013 na praia de Canoa Quebrada.

Tabela 2 -Evolução do Setor Hoteleiro na Praia de Canoa Quebrada

\begin{tabular}{|c|c|}
\hline Década & Hotéis \\
\hline $\begin{array}{c}\text { Antes de } \\
1990\end{array}$ & 5 \\
\hline 1990 & 25 \\
\hline 2000 & 69 \\
\hline 2013 & 84 \\
\hline
\end{tabular}

Fonte : SETUR/CE Souza Neto(2011), adaptado pelo autor.

Como se pode observar através dos dados relacionados na tabela (2), entre as décadas de 1970 e 1980, constata-se um crescimento mínimo com registro de 5 pousadas, embora existisse muitas casas com quartos para alugar. Já no intervalo, entre 1990 a 2000, percebe-se um aumento significativo correspondente ao número de meios de hospedagem. No período entre 1990 e 2005, há um crescimento em Canoa Quebrada decorrente de novas infraestruturas, que contribuem, positivamente, para o aumento na oferta de unidades habitacionais oferecidas pelos mais de 40 meios de hospedagem que surgiram no núcleo urbano de Canoa Quebrada, instalados, principalmente, após o ano 2000, aumentando a competitividade do mercado hoteleiro.

A demanda do número de turista na praia de Canoa Quebrada vem crescendo nos últimos anos, conforme a tabela 3. Assim sendo, o aumento do fluxo turístico contribuiu para o desenvolvimento do setor hoteleiro de Canoa Quebrada, assegurando um expressivo avanço que provocou o surgimento de uma nova organização territorial. 
Tabela 3 - Demanda de Turistas na Praia de Canoa Quebrada

\begin{tabular}{|c|c|c|c|}
\hline Ano & $\begin{array}{c}\text { Percentual } \\
\text { na Demanda } \\
(\mathbf{\%})\end{array}$ & Turista & $\begin{array}{c}\text { Permanência } \\
\text { (Dias) }\end{array}$ \\
\hline $\mathbf{2 0 0 9}$ & 8,22 & 208.400 & 5,3 \\
\hline $\mathbf{2 0 1 0}$ & 8,37 & 240.202 & 5,4 \\
\hline $\mathbf{2 0 1 1}$ & 8,37 & 275.401 & 5,0 \\
\hline $\mathbf{2 0 1 2}$ & 8,37 & 294.545 & 5,4 \\
\hline $\mathbf{2 0 1 3}$ & 8,37 & 300.697 & 6,50 \\
\hline
\end{tabular}

Fonte: Ceará(2015), adaptado pelo autor.

Conforme os dados apresentados na tabela 3, assim como o aumento da demanda, outro fator que ficou evidenciado foi o aumento da permanência do turista impulsionando o mercado de meios de hospedagem e de alimentação, bem como na diversificação dos serviços turísticos como passeios de buggy, souvenirs, entretenimentos e infraestrutura de apoio ao turismo como bancos, supermercado, posto policial etc. Dessa forma, ocorre um acelerado processo de urbanização que pode ser identificado através da otimização dos espaços para uso do setor hoteleiro que levou à destruição de muitas das edificações típicas de vila de pescadores, demolidas para atender às novas exigências da realidade local, situação comprovada, principalmente, através da construção de prédios na Broadway, para abrigar os meios de hospedagem e restaurantes.

Outro registro importante quanto aos hotéis desse período da década de 1970 e 1980, diz respeito a sua concentração numa área específica do centro urbano de Canoa, sem apresentar áreas de lazer e espaços para estacionamento. Já os hotéis inaugurados de 1990 a 2000 refletem uma tendência de modernização, acompanhando o novo padrão arquitetônico das construções dos grandes centros urbanos, ao mesmo tempo em que introduzem melhorias físicas e de serviços, tais como dormitórios com banheiro privativo, serviços completos de hotelaria e área de lazer com piscina.

Até 1990, o turismo, em Canoa Quebrada, era praticado por um público menos massificado; após a década de 1990, o mercado turístico dessa região teve a sua natureza modificada, fato que gerou um grande impacto espacial. Trata-se não apenas da transformação e da ampliação da ocupação diante dessa atividade, mas de uma mudança de qualidade e de abrangência do mercado, para atender um turista muito mais exigente em relação aos serviços de apoio. 


\section{CONSIDERAÇÕES FINAIS}

Ao longo desse artigo são discutidas, sobretudo, as transformações decorrentes do aumento do fluxo de turistas e seus reflexos na expansão do setor hoteleiro da praia de Canoa Quebrada. As mudanças ocorridas na organização sócio espacial desta localidade são fruto da expansão da atividade turística nas últimas décadas e culminam com o avanço do setor hoteleiro local.

Para Coriolano (2003), o turismo é uma das mais novas modalidades do processo de acumulação, que vem produzindo novas configurações geográficas e materializando espaços de forma contraditória, pela ação do estado, das empresas, dos residentes e dos turistas. Deste modo, as formas geográficas se alteram e mudam de valor e o espaço se modifica para atender às transformações da atividade turística.

Assim, a ação gerada pela atividade turística na Vila de Canoa Quebrada, ajudou na sua nova organização espacial formando um "território turístico", decorrente da relação dialética entre sociedade e natureza. Para Santos (2012) a sociedade e a natureza estabelece uma relação dialética, ou seja, a natureza influencia a vida dessa sociedade que, por sua vez, age de acordo com as características naturais daquele espaço. Portanto, é notório, o processo de aceleração, urbanização e crescimento dos fluxos turísticos na praia de Canoa Quebrada, que vem dando novas funções ao espaço que outrora era apenas uma vila de pescadores.

\section{REFERÊNCIAS}

Barros, N. P. (2004). Canoa e suas histórias (2a ed.). Mossoró: GL Gráfica Editura .

Boullón, R. C. (2005). Os Municípios Turísticos. Bauro, SP: Edusc.

Ceará, S. E. (2015). Indicadores Turísticos 1995/2014. Fortaleza: SETUR.

Coriolano, L. N. (2003). Os limites do Desenvolvimento e do turismo: O turismo de inclusão. e desenvolvimento local. Fortaleza: FUNECE.

Cruz, R. d. (2006). Planejamento governamental do turismo: convergência e contradições na produção do espaço. Anais da América Latina: cidade, campo e turismo, 337-350. São Paulo : Clacso .

Esmeraldo, L. R. (2002). Jangadeiros e pescadores: os dilemas do Turismo em Canoa Quebrada. Fortaleza: SENAC.

Gil, A. (2002). Como elabora projeto de pesquisa. São Paulo: Atlas. 
Grandelle, R. (2015). Aracati: muito além das falésias coloridas de Canoa Quebrada. Boa Viagem. Recuperado em 10 de agosto, 2015, de http://oglobo.globo.com/boa-viagem/aracatimuito-alem-das-falesias-coloridas-de-canoa-quebrada-3170322.

IBGE , I. (2015). Recuperado em 15 de agosto, 2015, de http://www.ibge.gov.br/home/.

Krippendorf, J. (2009). Sociologia do Turismo: para uma nova compreensão do lazer e das viagens (3a ed.). São Paulo: Aleph .

Pereira, R. F. (2013). O Sistema Rodoviário e o Turismo no litoral do estado de Santa Catarina. Turydes.

Pousada Lua Morena. (2013). Recuperado em 10 de junho, 2013, de http:/pousadaluamorena.com.br/index.php/pousada/a-pousada-sua-historia-e-seu-futuro/

Richardson, R. J. (1999). Pesquisa Social: métodos e técnicas. São Paulo: Atlas.

Santos, M. (1986). Pensando o espaço do humem. São Paulo: Hucitec.

Santos, M. (2012). Espaço e Método. São paulo: Universidade de São Paulo.

SETUR-CE. (2015). Recuperado em 25 de julho, 2015, de http://www.setur.ce.gov.br/noticias/ceara-deve-receber-364-mil-turistas-nas-ferias-de.1

Siqueira , F. de S. (2013). Aracati/Ce das charqueadas ao polo turístico de Canoa Quebrada. Mestrado em Turismo e hotelaria - Universidade Vale do Jaguaribe , 189.

Souza Neto, G. F. (2011). Dissetação de Mestrado. O Estado em ação: produção espacial pelas Políticas de Turismo em Aracati/CE. Fortaleza : Dissertação (Mestrado em Geografia) Universidade Estadual do (?).

Thiollent, M. (1997). Pesquisa-ação nas organizações. São Paulo: Atlas. 